\title{
Unexpected Serotypes of Mycoplasmas Isolated from Pigs
}

\author{
By D. TAYLOR-ROBINSON \\ M.R.C. Clinical Research Centre, Harvard Hospital, Salisbury, England \\ AND Z. DINTER \\ Institute of Virology, Royal Veterinary College and National Veterinary \\ Institute, Stockholm, Sweden \\ (Accepted for publication 4 April 1968)
}

\begin{abstract}
SUMMARY
Several mycoplasmas isolated from pigs and designated B strains were previously found to be different from Mycoplasma hyorhinis and $M$. granularum, and to comprise four distinct serotypes. In the present study three of these serotypes were identified as $M$. laidlawii, $M$. gallinarum and $M$. iners, respectively. One serotype represented by mycoplasma B3 could not be identified. The isolation of avian serotypes from pigs is discussed in the light of host specificity of mycoplasmas.
\end{abstract}

\section{INTRODUCTION}

Mycoplasma hyorhinis and M. granularum were first isolated some years ago from pigs (Switzer, 1955, 1964) and many times subsequently. Dinter, Danielsson \& Bakos (I965) described several mycoplasmas isolated from pigs, some of which (SEP strains) were identified as $M$. hyorhinis. The remainder, designated B strains, were neither $M$. hyorhinis nor $M$. granularum; on the basis of agar gel diffusion and growth inhibition studies they comprised four distinct serotypes. In the present study most of the B strains have been identified as previously named mycoplasmas, by using metabolicinhibition and growth-inhibition techniques. The specificity of mycoplasmas in tissue culture systems and in vivo is discussed in the light of the findings.

\section{METHODS}

Mycoplasma strains. The strains from pigs have been described previously (Dinter et al. 1965). In the present study two reference strains, $M$. hyorhinis $\mathrm{F}$ and $M$. granularum, and six B strains, BI to B6, were compared with mycoplasmas isolated from sources other than the pig. The following serotypes were used: $M$. anatis, $M$. gallinarum, $M$. gallisepticum, $M$. iners, $M$. meleagridis, $M$. synoviae, IOWA 695 , WRI, I86, 658, $M$. bovigenitalium, $M$. mycoides, DONETTA, DI2, N29, 5M33I, $M$. canis, $M$. maculosum, $M$. spumans, $M$. agalactiae, $M$. mycoides var. capri, $M$. hominis, $M$. fermentans, $M$. orale I, $M$. orale 2, $M$. pneumoniae, $M$. salivarium, $M$. arthritidis, $M$. histotropicus, $M$. neurolyticum, $M$. pulmonis, $\mathrm{PG} 5$ and $M$. laidlawii. In addition, $M$. hyorhinis strains SEP SK (Dinter et al. 1965) and GDL (Purcell et al. 1966a) were used for antibody studies. Stock mycoplasma cultures were stored at $-70^{\circ}$ in liquid medium and were titrated for viable organisms before use in the serological tests. 
Mycoplasma media. Liquid medium consisted of Difco PPLO broth containing $20 \%(\mathrm{v} / \mathrm{v})$ unheated Burroughs Wellcome no. 6 horse serum, Io \% (v/v) of $25 \%(\mathrm{w} / \mathrm{v})$ extract of dried yeast (Distillers Co. Ltd.), I/2000 thallium acetate, I000 u. penicillin/ $\mathrm{ml}$. and $0.002 \%$ phenol red. In addition, this medium contained either $0 . \mathrm{I} \%$ glucose or $0.1 \%$ arginine. Solid medium consisted of the liquid medium with the addition of r \% Oxoid Ionagar no. 2.

Titration of viable organisms. The principle of the method has been described before (Taylor-Robinson \& Purcell, I966). For those strains which metabolize glucose, $0 \cdot \mathrm{I} \%$ glucose was incorporated in the medium which was adjusted to $\mathrm{pH} 7 \cdot 8$. For those strains which metabolize arginine, $0.1 \%$ arginine was incorporated in the medium adjusted to $\mathrm{pH} 7 \cdot 0$. Serial tenfold dilutions of a mycoplasma suspension were made in liquid medium contained in screw-capped vials. The vials were incubated at $37^{\circ}$ until the colour of the medium ceased to change. The highest dilution of the mycoplasma suspension which caused a colour change was regarded as the end-point of the titration. In addition, in some instances, $0.1 \mathrm{ml}$. amounts of the dilutions were inoculated on agar medium and these cultures incubated at $37^{\circ}$ in an atmosphere of $95 \%$ $(\mathrm{v} / \mathrm{v})$ nitrogen $+5 \%(\mathrm{v} / \mathrm{v})$ carbon dioxide. Colonies were counted when new colonies ceased to develop.

Rabbit antisera. Antisera to Mycoplasma hyorhinis strain F, $M$. granularum and to mycoplasma strains BI to B6 were those described and used previously (Dinter et al. 1965). Antisera to other mycoplasma species were prepared in rabbits also. All sera were stored at $-20^{\circ}$ and were heated at $56^{\circ}$ for $30 \mathrm{~min}$. before use.

Growth inhibition on agar medium. The technique was that of Clyde (1964). Stock mycoplasma cultures, previously titrated, were diluted in medium so that $0 \cdot 1 \mathrm{ml}$. contained about $10^{5}$ colony-forming units. This was spread on the agar medium which had been dried for $30 \mathrm{~min}$. at $37^{\circ}$ before inoculation. Filter-paper discs $(7 \mathrm{~mm}$. diameter) were soaked with $0.025 \mathrm{ml}$. of undiluted antiserum and were placed on the agar. Zones of inhibition were recorded after incubation at $37^{\circ}$ in $95 \%(v / v)$ nitrogen + $5 \%(\mathrm{v} / \mathrm{v})$ carbon dioxide. Zones were measured from the edge of the disc to the edge of colony development.

Metabolic inhibition. The techniques previously described by Taylor-Robinson, Purcell, Wong \& Chanock (I966), and by Purcell, Taylor-Robinson, Wong \& Chanock (1966 b) were used. In some tests, unheated guinea-pig serum was used at a final concentration of $3 \%(\mathrm{v} / \mathrm{v})$. Results were recorded when a colour change of about half a $\mathrm{pH}$ unit had occurred in the controls containing mycoplasma organisms but no antiserum.

\section{RESULTS}

\section{Metabolism of mycoplasma strains isolated from pigs}

In order to use the metabolic-inhibition test it was necessary to determine which substrate, glucose or arginine, was metabolized by each strain. Mycoplasma hyorhinis, $M$. granularum and strains B3 and B4 metabolized glucose but not arginine. Strains BI, B2 and B5 metabolized glucose poorly, and metabolized arginine also, while strain $\mathrm{B} 6$ metabolized arginine and not glucose. In subsequent metabolic-inhibition tests arginine was used for strains BI, B2 and B5. 


\section{Relationship between mycoplasma strains isolated from pigs}

The porcine strains originally isolated by Bakos \& Dinter (I963) were examined by the metabolic-inhibition technique. A rabbit antiserum prepared against each mycoplasma strain was tested against all the strains in the presence of unheated guinea-pig serum. Strictly, however, this was essential only in tests with B3 antiserum, the homologous titre of which was decreased at least 64 -fold in the absence of guinea-pig serum. The results are shown in Table I. Mycoplasma hyorhinis, $M$. granularum and strains B3, B4 and B6 were different from each other. Strains BI, B2 and B5 were closely

Table I. Relationship between mycoplasma strains isolated from pigs as shown by the metabolic-inhibition technique

\begin{tabular}{|c|c|c|c|c|c|c|c|}
\hline \multirow[b]{2}{*}{ Mycoplasma } & \multicolumn{7}{|c|}{ Reciprocal of metabolic-inhibition titre with rabbit antisera to } \\
\hline & $\begin{array}{l}\text { M. hyo- } \\
\text { rhinis } \mathrm{F}\end{array}$ & $\begin{array}{c}\text { M. granu- } \\
\text { larum }\end{array}$ & BI & B2 & B3 & B4 & в6 \\
\hline M. hyorhinis $\mathrm{F}$ & 1280 & $<20$ & $<20$ & $<20$ & $<20$ & $<20$ & $<20$ \\
\hline M. granularum & $<20$ & 320 & $<20$ & $<20$ & $<20$ & $<20$ & $<20$ \\
\hline BI & $<20$ & $<20$ & $\mathbf{1 2 8 0}$ & 640 & $<20$ & $<20$ & $<20$ \\
\hline B2 & nt & nt & 640 & 640 & $\mathrm{nt}$ & nt & nt \\
\hline B5 & nt & nt & 640 & 320 & $\mathrm{nt}$ & nt & nt \\
\hline B3 & $<20$ & $<20$ & $<20$ & $<20$ & 5120 or $>$ & $<20$ & $<20$ \\
\hline B4 & $<20$ & $<20$ & $<20$ & $<20$ & $<20$ & 40 & $<20$ \\
\hline B6 & $<20$ & $<20$ & 40 & 20 & $<20$ & $<20$ & 1280 \\
\hline
\end{tabular}

Table 2. Relationship of mycoplasma strains $B I, B 2$ and $B 5$ to Mycoplasma gallinarum

Reciprocal of metabolic-inhibition titre and zone of inhibition with rabbit antisera to

\begin{tabular}{lrrr} 
Mycoplasma & BI & B2 & $M$. gallinarum \\
B1 & I280 $(3 \cdot 2)^{*}$ & $640(\mathrm{I} \cdot 6)$ & $640(2 \cdot 6)$ \\
B2 & $640(2 \cdot 5)$ & $640(2 \cdot 5)$ & $320(2 \cdot 4)$ \\
B5 & $640(2 \cdot 8)$ & $320(2 \cdot 6)$ & $320(4 \cdot 0)$ \\
M. gallinarum & $2560(2 \cdot 1)$ & $640(\mathrm{I} \cdot 8)$ & $2560(2 \cdot 8)$ \\
\multicolumn{3}{l}{} \\
& * In parentheses: zone of inhibition in mm.
\end{tabular}

related to each other but distinct from the other mycoplasmas. These results confirmed those previously recorded by Dinter et al. (1965) who used gel diffusion and growthinhibition tests. However, none of the mycoplasmas, including $M$. hyorhinis and $M$. granularum, had previously been adequately examined for their relationship to other known mycoplasmas. Therefore, in the first instance, rabbit antiserum to each mycoplasma strain was tested against a variety of known mycoplasmas in the metabolicinhibition test. When the results suggested a relationship with a known mycoplasma serotype, the rabbit antisera were examined in growth-inhibition tests, and, in addition, antiserum to the known species in question was tested also against the particular porcine mycoplasma strain. 


\section{Relationship of mycoplasma strains BI, B2 and B5 to Mycoplasma gallinarum}

The results presented in Table 2 clearly show that strains BI, B2 and B5, known to be related to one another, are closely related to Mycoplasma gallinarum and may be regarded as strains of this known mycoplasma species. Biochemically, $M$. gallinarum was found to resemble strains BI, B2 and B5 in metabolizing both arginine and glucose, the latter poorly.

\section{Relationship of mycoplasma strain B4 to Mycoplasma laidlawii}

Antisera to Mycoplasma laidlawii inhibited this mycoplasma to low titre in metabolicinhibition tests but gave wide zones of inhibition on agar. This was a finding not usually observed with other mycoplasmas. Since the B4 antiserum behaved likewise in tests with its homologous organism it raised the possibility that strain B4 was a strain of $M$. laidlawii. The results in Table 3 show that this is so. Metabolic-inhibition titres were low and were not enhanced by addition of unheated guinea-pig serum to the tests, whereas zones of inhibition on agar were readily observed. In addition, further evidence for the relationship was obtained in the following manner. When strain $\mathbf{B} 4$ was tested against its homologous rabbit antiserum by the disc inhibition method, several colonies were observed within the general zone of inhibition. Each of these 'within zone' colonies was cloned, propagated in liquid medium and then these materials were retested in both metabolic-inhibition and disc growth-inhibition tests against B4 and $M$. laidlawii antisera. Organisms grown from each 'within zone' colony were inhibited to low titre (20-40) in metabolic-inhibition tests with both $\mathrm{B} 4$ and $M$. laidlawii antisera; wide zones of inhibition on agar were observed with both antisera. Subsequent to these serological investigations, a culture of strain B4 was diluted in serial ten-fold steps in mycoplasma broth without horse serum and inoculated on agar medium without serum. On incubation at $37^{\circ}$, colonies developed as well on the serum-free medium as on medium with $20 \%(\mathrm{v} / \mathrm{v})$ horse serum, indicating the biological similarity of strain $\mathrm{B} 4$ to $M$. laidlawii.

Table 3. Relationship of mycoplasma strain B4 to Mycoplasma laidlawii
$\begin{gathered}\text { Reciprocal of metabolic-inhibition titre } \\ \text { and zone of inhibition with rabbit } \\ \text { antisera to }\end{gathered}$
$\begin{array}{ccc}\text { Mycoplasma } & \text { B. laidlawii } \\ \text { B4 } 4 & 40(4 \cdot 6)^{*} & 80(3 \cdot 0) \\ \text { M. laidlawii } & 40(\mathrm{I} \cdot 3) & 80(\mathrm{I} \cdot 5) \\ * \text { In parentheses: zone of inhibition in } \mathrm{mm} .\end{array}$

Relationship of mycoplasma strain B6 to Mycoplasma iners

The results in Table 4 show that strain $\mathrm{B} 6$ is closely related to Mycoplasma iners. B6 antiserum did not inhibit $M$. iners to as high a titre as it did its homologous organism in a metabolic-inhibition test. However, $M$. iners antiserum inhibited $\mathbf{8} 6$ and its homologous organism to an equal titre. Biochemically, $M$. iners was found to resemble strain $\mathrm{B} 6$ in metabolizing arginine and not glucose. 
Serological examination of Mycoplasma hyorhinis, M. granularum and mycoplasma strain $B 3$

Antisera to these three strains were examined in metabolic-inhibition tests against the mycoplasma serotypes listed in Methods. No cross-reactions were observed. In addition, antisera to some of the mycoplasmas listed in Methods were tested against strain $\mathbf{B} 3$ in metabolic-inhibition and growth-inhibition tests but no evidence of a relationship with a known mycoplasma species was obtained.

\section{Metabolic-inhibition tests with randomly collected avian and porcine sera}

No sera were available from the pigs from which the mycoplasma strains were isolated. However, the strains were tested against about 40 randomly collected pig sera and 30 randomly collected chicken sera. The occurrence of antibody is shown in Table 5. Antibody to Mycoplasma hyorhinis in the porcine sera was detected with strain GDL, but not with strain SEP SK. Variations in the ability of different strains of a serotype to detect antibody have been observed also with strains of $M$. gallisepticum (D. Taylor-Robinson \& D. M. Berry, unpublished). Antibody to M. granularum in

Table 4. Relationship of mycoplasma strain B6 to Mycoplasma iners

\begin{tabular}{|c|c|c|}
\hline \multirow[b]{2}{*}{ Mycoplasma } & \multicolumn{2}{|c|}{$\begin{array}{c}\text { Reciprocal of metabolic-inhibition titre } \\
\text { and zone of inhibition with rabbit } \\
\text { antisera to }\end{array}$} \\
\hline & в6 & $M$. iners \\
\hline $\begin{array}{l}\text { в6 } \\
M . \text { iners }\end{array}$ & $\begin{array}{c}1280(4 \cdot 2)^{*} \\
160(2 \cdot 8)\end{array}$ & $\begin{array}{l}1280(2 \cdot 7) \\
1280(2 \cdot 6)\end{array}$ \\
\hline
\end{tabular}

Table 5. Antibody to various mycoplasmas in random porcine and avian sera measured by the metabolic-inhibition technique

\begin{tabular}{lcc}
\multicolumn{1}{c}{ Mycoplasma } & \multicolumn{2}{c}{$\begin{array}{c}\text { Percentage of indicated sera } \\
\text { containing antibody* }\end{array}$} \\
\cline { 2 - 3 } $\begin{array}{l}\text { Porcine } \\
\text { M. hyorhinis SEP SK }\end{array}$ & $\begin{array}{c}\text { Avian } \\
M . \text { granularum }\end{array}$ & $\mathrm{nt}$ \\
BI & 0 & $\mathrm{nt}$ \\
$M$. gallinarum & 0 & $\mathrm{nt}$ \\
B3 & 2 & 95 \\
B6 & 45 & $\mathrm{nt}$ \\
$M$. iners & $\mathrm{I} 4$ & 34 \\
nt $=$ not tested. & $*$ At a dilution of $\mathrm{I} / 2$ or greater.
\end{tabular}

the porcine sera was not detected; this may have been due to the use of an antibodyinsensitive strain. Antibody to strain BI was not detected in porcine sera and antibody to the prototype $M$. gallinarum was rarely detected. However, antibody to strain BI was detected in avian sera, suggesting the occurrence of this strain in birds rather than in pigs. Antibody to strain B3 was found in both porcine and avian sera which did not help, therefore, in assessing the natural host. Strain B6 and the proto- 
type $M$. iners behaved similarly. The occurrence of antibody to $M$. iners in porcine sera may be indicative of occasional infection of pigs with this mycoplasma or, alternatively, it may be a heterotypic response due to a possible sharing of antigens between $M$. iners and other mycoplasmas infecting pigs.

\section{DISCUSSION}

The major point to be discussed concerns the host specificity of mycoplasmas. Specificity may be viewed at several levels. At the cellular level it would seem that there is little difficulty in infecting tissue culture cells derived from several avian or mammalian species with a mycoplasma isolated from one of them. Some examples of this are presented in Table 6 . It is possible also experimentally to infect animals or birds of one species with a mycoplasma derived from another. Thus, infection of sheep and goats has been achieved by the subcutaneous inoculation of Mycoplasma mycoides

Table 6. Examples of mycoplasma infection of tissue culture cells

\begin{tabular}{|c|c|c|c|c|}
\hline \multicolumn{2}{|c|}{ Mycoplasmas } & \multicolumn{2}{|c|}{ Tissue culture cells } & \multirow[b]{2}{*}{ Reference } \\
\hline Designation & Origin & Origin & CPE & \\
\hline M. pneumoniae & Man & Monkey kidney* & - & Chanock et al. (1960) \\
\hline M. orale $\mathrm{I}$ & Man & Chick embryo* & + & Somerson \& Cook (1965) \\
\hline M. hominis & Man & Hamster kidney (BHK 2I) & + & Macpherson \& Russell (1966) \\
\hline M. pulmonis & Rodent & Man (HeLa) & + & Nelson (1960) \\
\hline M. hyorhinis & Pig & Man (HEp-2) & + & Butler \& Leach (1964) \\
\hline M. bovigenitalium & Cattle & Pig kidney* & + & Afshar (1967) \\
\hline
\end{tabular}

Table 7. Some evidence against host specificity of mycoplasmas

(i) Isolation studies

(a) M. arthritidis from human collagen disease (Jansson \& Wager, 1967)

(b) $M$. hyorhinis from human bladder papilloma (Hayflick \& Stanbridge, 1967)

(c) M. agalactiae affects sheep and goats (Hudson et al. 1967)

(d) $M$. laidlawii from various animals (see text)

(ii) Antibody studies

E.g. M. hyorhinis metabolic-inhibition antibody in human sera (D. Taylor-Robinson \& R. H. Purcell, unpublished).

from cattle (Turner, Campbell \& Dick, 1935) and infection of cotton rats and hamsters by the intranasal inoculation of $M$. pneumoniae from man (Eaton, Meiklejohn \& van Herick, I944; Dajani, Clyde \& Denny, I965). However, experimental inoculation may often be unsuccessful, probably because in vivo immune mechanisms play a part in preventing infection. For example, Switzer (1967) failed to infect mice, chickens, turkeys, calves, guinea pigs, hamsters, rabbits or sheep with $M$. hyorhinis isolated from pigs. Furthermore, under natural, as opposed to experimental, conditions there would seem to be an even greater degree of host specificity. In addition to immunological factors this may be due to the smaller number of mycoplasmas likely to be encountered under natural conditions. While in many instances there would appear to be a real host specificity, in others it is possible that this is more apparent than real. Apparent host specificity might arise from lack of opportunity to infect under natural conditions or because no attempts have been made to determine whether or not a 
particular mycoplasma is capable of infecting another avian or mammalian species. From the foregoing it is clear that mycoplasma host specificity exists but that it is not likely to be absolute. In Table 7 some evidence is presented that under natural conditions specificity is not absolute. Whether the results of the present investigation represent further evidence against host specificity is open to question.

One of the strains, B4, was identified as Mycoplasma laidlawii. This is of interest serologically since in previous gel diffusion tests (Dinter et al. 1965) reciprocal crossreactions of low order were noted between B4 and $M$. granularum, and Tully (I966) has reported a partial relationship of $M$. granularum strains with a $M$. laidlawii A strain (PG-8) in immunofluorescence tests. The finding of $M$. laidlawii in pigs would certainly not be inconsistent with the finding of this mycoplasma in other species by other workers. Thus, since its isolation from sewage (Laidlaw \& Elford, 1936), it has been found in chickens (Adler, Shifrine \& Ortmayer, 196I), man (Razin, Michmann \& Shimshoni, 1964), cattle (Leach, 1967) and horses (D. Taylor-Robinson \& S. P. Beveridge, unpublished); this, presumably, is reason enough for its presence in sewage.

The strains BI, B2 and B5 were identified as Mycoplasma gallinarum and B6 as $M$. iners, both these serotypes having been reported hitherto as occurring only in birds (Edward \& Kanarek, I960; Roberts, 1964; Dierks, Newman \& Pomeroy, 1967). The isolation of avian serotypes from pigs raises the question of whether these mycoplasmas were, in fact, laboratory contaminants. Evidence against this idea is that all the isolations were made directly on mycoplasma medium and not through embryonated eggs and that strains BI, B2 and B5 were isolated at different times over a period of two years. It is of interest also that all B strains were isolated from pigs having pneumonia, with or without rhinitis. It is conceivable that damaged respiratory tract tissue might be susceptible to colonization by saprophytic or 'unrelated' mycoplasmas. On the other hand, it should be pointed out that specimens from birds were examined within the same laboratory, although stock cultures of $M$. gallinarum and $M$. iners were never handled. We thought that serological examination of random avian and porcine sera might help to determine the source of the mycoplasmas. However, the data are difficult to interpret. The occurrence of antibody to strain BI in the sera of chickens but not pigs certainly suggests an avian host, although it might be possible for infection of pigs to occur occasionally without antibody development. The occurrence of antibody to strain $\mathrm{B} 6$ in pig sera might be due to specific infection or to infection with an antigenically related strain. Therefore, although we feel laboratory contamination is an unlikely explanation for our findings it is obviously not possible to resolve this point unequivocally. Nevertheless, our observations should at least make others aware that mycoplasmas generally associated with a particular species might infect another unrelated species and so stimulate further investigation. Our findings reemphasize the need to test strains against all known mycoplasmas, and not merely against those commonly isolated from the same animal or bird, before regarding them as new species.

We thank Mrs Susan Beveridge for excellent technical assistance and Dr K. Bakos, National Veterinary Institute, Stockholm, for the collection of pig sera.

The M.R.C. Clinical Research Centre, Harvard Hospital, Salisbury, England, receives support, gratefully acknowleged, from the World Health Organization for reference work on mycoplasmas. 


\section{REFERENCES}

Adler, H. E., Shifrine, M. \& ORTMAYER, H. (I96I). Mycoplasma inocuum sp.n., a saprophyte from chickens. J. Bact. 82, 239.

AfshaR, A. (1967). The growth of Mycoplasma bovigenitalium in cell cultures. J. gen. Microbiol. 47, 103.

Bakos, K. \& Dinter, Z. (I963). Das SEP-Agens. Proc. I7th World Vet. Congr. r, 549.

Butler, M. \& Leach, R. H. (1964). A mycoplasma which induces acidity and cytopathic effect in tissue culture. J. gen. Microbiol. 34, 285.

Chanock, R. M., Fox, H. H., James, W. D., Bloom, H. H. \& Mufson, M. A. (1960). Growth of laboratory and naturally occurring strains of Eaton agent in monkey kidney tissue culture. Proc. Soc. exp. Biol. Med. 105, 37 I.

Clyde, W. A. Jun. (1964). Mycoplasma species identification based upon growth inhibition by specific antisera. J. Immunol. 92, 958.

Dajani, A. S., Clyde, W. A. Jun. \& Denny, F. W. (1965). Experimental infection with Mycoplasma pneumoniae (Eaton's agent). J. exp. Med. 121, 1071.

Dierks, R. E., Newman, J. A. \& Pomeroy, B. S. (1967). Characterization of avian mycoplasma. Ann. N.Y. Acad. Sci. r43, 170.

Dinter, Z., DANielsson, D. \& Bakos, K. (1965). Differentiation of porcine mycoplasma strains. J. gen. Microbiol. 4I, 77.

Eaton, M. D., Merklejohn, G. \& van Herick, W. (I944). Studies on the etiology of primary atypical pneumonia. A filterable agent transmissible to cotton rats, hamsters, and chick embryos. $J$. exp. Med. 79, 649.

EDWARD, D. G. ff. \& KanAREK, A. D. (1960). Organisms of the pleuropneumonia group of avian origin: their classification into species. Ann. N.Y. Acad. Sci. 79, 696.

Hayflick, L. \& Stanbridge, E. (I967). Isolation and identification of mycoplasma from human clinical materials. Ann. N.Y. Acad. Sci. 143, 608.

Hudson, J. R., Cottew, G. S. \& AdleR, H. E. (1967). Diseases of goats caused by mycoplasma: a review of the subject with some new findings. Ann. N.Y. Acad. Sci. 143, 287.

JANsson, E. \& WAGER, O. (1967). Mycoplasma in collagen diseases and blood dyscrasia. Ann. N.Y. Acad. Sci. 143, 535.

Laidlaw, P. P. \& Elford, W. J. (1936). A new group of filterable organisms. Proc. R. Soc. B rzo, 292.

LEACH, R. H. (1967). Comparative studies of mycoplasma of bovine origin. Ann. N.Y. Acad. Sci. I43, 305.

MACPherson, I. \& Russell, W. (1966). Transf, aations in hamster cells mediated by mycoplasmas. Nature, Lond. 210, I 343.

Nelson, J. B. (I960). The behaviour of murine PPLO in HeLa cell cultures. Ann. N.Y. Acad. Sci. 79,450 .

Purcell, R. H., Somerson, N. L., Fox, H., Wong, D. C., Turner, H. C. \& Chanock, R. M. (1966a). Identification of acid-inducing agent and related mycoplasmas as M. hyorhinis. J. natn. Cancer Inst. 37, $25 \mathrm{I}$.

Purcell, R. H., Taylor-Robinson, D., Wong, D. C. \& Chanock, R. M. (I966b). A color test for the measurement of antibody to the non-acid-forming human mycoplasma species. Am.J. Epidemiol. 84, 5I.

Razin, S., Michmann, J. \& Shimshoni, Z. (1964). The occurrence of Mycoplasma (pleuropneumonialike organisms, PPLO) in the oral cavity of dentulous and edentulous subjects. $J$. dent. Res. 43, 402 .

RoBerTs, D. H. (1964). Serotypes of avian mycoplasma. J. comp. Path. Therap. 74, 447.

Somerson, N. L. \& CooK, M. K. (I965). Suppression of Rous sarcoma virus growth in tissue cultures by Mycoplasma orale. J. Bact. 90,534 .

SwItzer, W. P. (1955). Studies on infectious atrophic rhinitis. IV. Characterization of a pleuropneumonia-like organism isolated from the nasal cavities of swine. Am. J. vet. Res. 16, 540.

Switzer, W. P. (1964). Mycoplasmosis. In Diseases of Swine, 2nd ed. Ed. by H. W. Dunne. P. 498. Ames, Iowa: Iowa State University Press.

SwITZER, W. P. (1967). Swine mycoplasmosis. Ann. N.Y. Acad. Sci. 143, 281. 
TAYLOR-RoBinson, D. \& PURCelL, R. H. (1966). Mycoplasmas of the human urogenital tract and oropharynx and their possible role in disease: a review with some recent observations. Proc. $R$. Soc. Med. 59, Iri2.

Taylor-Robinson, D., Purcell, R. H., Wong, D. C. \& Chanock, R. M. (1966). A colour test for the measurement of antibody to certain mycoplasma species based upon the inhibition of acid production. J. Hyg., Camb. 64, 91 .

TulLY, J. G. (1966). Mycoplasma granularum of swine origin as a tissue culture contaminant. Proc. Soc. exp. Biol. Med. 122, 565.

TURNer, A. W., CAMPBell, A. D. \& Dick, A. T. (1935). Recent work on pleuro-pneumonia contagiosa boum in North Queensland. Aust. vet. J. 11, 63. 